\title{
In situ expression of $(R)$-carbonyl reductase rebalancing an asymmetric pathway improves stereoconversion efficiency of racemic mixture to $(S)$-phenyl-1,2-ethanediol in Candida parapsilosis CCTCC M203011
}

Rongzhen Zhang ${ }^{1,2,4^{*}}$, Lei Wang ${ }^{1}$, Yan $\mathrm{Xu}^{1,2,4^{*}}$, Hongbo Liang ${ }^{1}$, Xiaotian Zhou ${ }^{1}$, Jiawei Jiang ${ }^{1}$, Yaohui Li ${ }^{1}$, Rong $\mathrm{XiaO}^{3}$ and $\mathrm{Ye} \mathrm{Ni}^{1}$

\begin{abstract}
Background: Candida parapsilosis (R)-carbonyl reductase (RCR) and (S)-carbonyl reductase (SCR) are involved in the stereoconversion of racemic (R,S)-1-phenyl-1,2-ethanediol (PED) to its (S)-isomer. RCR catalyzes (R)-PED to 2-hydroxyacetophenone (2-HAP), and SCR catalyzes 2-HAP to (S)-PED. However, the stereoconversion efficiency of racemic mixture to (S)-PED is not high because of an activity imbalance between RCR and SCR, with RCR performing at a lower rate than SCR. To realize the efficient preparation of racemic mixture to (S)-PED, an in situ expression of RCR and a twostage control strategy were introduced to rebalance the RCR- and SCR-mediated pathways.

Results: An in situ expression plasmid pCP was designed and RCR was successfully expressed in C. parapsilosis. With respect to wild-type, recombinant C. parapsilosis/pCP-RCR exhibited over four-fold higher activity for catalyzing racemic (R,S)-PED to 2-HAP, while maintained the activity for catalyzing 2-HAP to (S)-PED. The ratio of $k_{\text {cat }} / K_{M}$ for SCR catalyzing (R)-PED and RCR catalyzing 2-HAP was about 1.0, showing the good balance between the functions of SCR and RCR. Based on $\mathrm{pH}$ and temperature preferences of RCR and SCR, a two-stage control strategy was devised, where $\mathrm{pH}$ and temperature were initially set at 5.0 and $30^{\circ} \mathrm{C}$ for RCR rapidly catalyzing racemic PED to 2-HAP, and then adjusted to 4.5 and $35^{\circ} \mathrm{C}$ for SCR transforming 2-HAP to (S)-PED. Using these strategies, the recombinant C. parapsilosis/pCPRCR catalyzed racemic PED to its (S)-isomer with an optical purity of $98.8 \%$ and a yield of $48.4 \%$. Most notably, the biotransformation duration was reduced from 48 to $13 \mathrm{~h}$.
\end{abstract}

Conclusions: We established an in situ expression system for RCR in C. parapsilosis to rebalance the functions between RCR and SCR. Then we designed a two-stage control strategy based on $\mathrm{pH}$ and temperature preferences of RCR and SCR, better rebalancing RCR and SCR-mediated chiral biosynthesis pathways. This work demonstrates a method to improve chiral biosyntheses via in situ expression of rate-limiting enzyme and a multi-stage control strategy to rebalance asymmetric pathways.

Keywords: (R)-carbonyl reductase, Candida parapsilosis, In situ expression, Racemic 1-phenyl-1,2-ethanediol, Stereoconversion, (S)-1-phenyl-1,2-ethanediol

\footnotetext{
*Correspondence: rzzhang@jiangnan.edu.cn; yxu@jiangnan.edu.cn

${ }^{4}$ Present Address: School of Biotechnology, Jiangnan University, 1800

Lihu Avenue, Wuxi 214122, People's Republic of China

Full list of author information is available at the end of the article
} 


\section{Background}

Optically active alcohols are versatile chiral building blocks for organic synthesis in a variety of different industries. Considerable research efforts have recently focused on the preparation of chiral compounds using enzyme-catalyzed bioprocesses [1, 2]. Stereospecific carbonyl reductases are good candidates to catalyze prochiral ketones to the corresponding enantiopure alcohols [3-5]. For example, Candida parapsilosis CCTCC M203011 contains $(R)$ - and (S)-carbonyl reductases (RCR and SCR), which catalyze the biotransformation of the valuable, optically active (S)-1-phenyl-1,2-ethanediol (PED) (Fig. 1), which can be used for synthesis of an antidepressant drug, fluoxetine, which extends the effects of 5-hydroxy tryptamine through selective inhibition for the extraction of 5-hydroxy tryptamine in central nervous system $[6,7]$. The enzymatic biosynthesis of $(S)$-PED involves two sequential redox reactions: (i) RCR catalyzes reversible conversion of 2-hydroxyacetophenone (2-HAP) to (R)-PED; and (ii) SCR catalyzes reduction of the intermediate 2-HAP to (S)-PED. The asymmetric flux of this process is controlled by the activity of the RCR and SCR enzymes, with the initial RCR-catalyzed reaction being the rate-limiting step. It was reported that wild-type (WT) C. parapsilosis and recombinant Escherichia coli containing RCR and SCR biotransform $(R)$-PED to the corresponding $(S)$-isomer with low yields, most likely because of the unbalanced efficiency of turnover of the enzymes $[8,9]$.

Many carbonyl reductases have been engineered in different host cells to improve their catalytic activity and/or protein production $[10,11]$. However, some recombinant

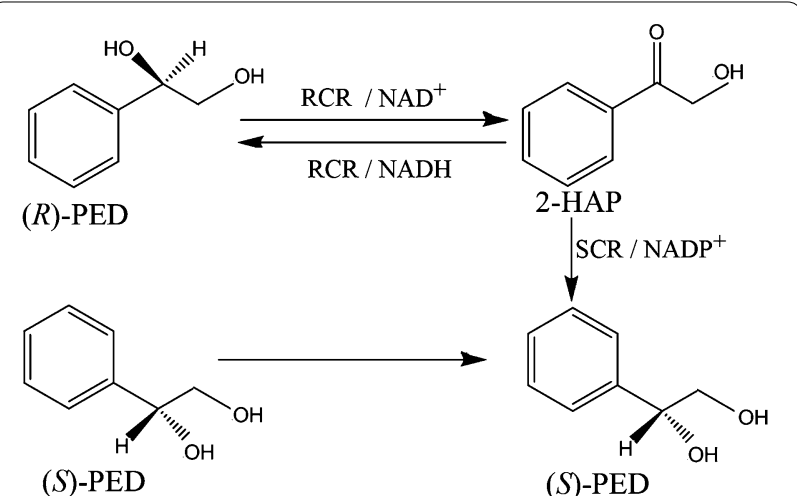

$(S)$-PED

(S)-PED

Fig. 1 The stereoinversion of, $(R, S)-P E D$ to its (S)-isomer by $R C R$ and SCR from C. parapsilosis. An NAD ${ }^{+}$-dependent RCR catalyzes the reversible reaction between (R)-PED and 2-HAP. An NADPH-linked SCR transforms the intermediate 2-HAP to (S)-PED. The oxidation of $(R)$-PED to 2-HAP is rate-limiting step during the stereoinversion of racemic ( $R, S)$-PED to its (S)-isomer. The desired product (S)-PED is underlined. PED, 1-phenyl-1,2-ethanediol; RCR, (R)-carbonyl reductase; SCR, (S)-carbonyl reductase carbonyl reductases have been reported to exhibit low or no enzymatic activity, which could be caused by incorrect protein folding or lack of post-translational modifications $[11,12]$. For example, the specific activities of carbonyl reductase and pyranose dehydrogenase expressed in yeast were much higher than those in E. coli $[13,14]$.

In our previous study, we successfully expressed the RCR and SCR enzymes of C. parapsilosis in different host cells, including E. coli [15], Saccharomyces cerevisiae [16] and Pichia pastoris $[13,17]$. Unfortunately, these recombinant enzymes produced the desired chiral PED with low yields over a long reaction time of $48 \mathrm{~h}$ [13, 15-17]. The recently developed in situ expression technique offers a new approach for increasing protein activity and production since the natural host supplies the better environment for protein-folding than heterogenous host. Yang et al. efficiently produced 2,3-butanediol using an in situ expression system containing glyceraldehyde3-phosphate dehydrogenase and 2,3-butanediol dehydrogenase in Bacillus amyloliquefaciens [18]. Piskin et al. proved that in situ expression of IL-23 by keratinocytes in healthy skin and psoriasis lesions enhanced expression in psoriatic skin [19]. Kasai et al. reported increased expression of type I 17 $\beta$-hydroxysteroid dehydrogenase enhances in situ production of estradiol in uterine leiomyoma [20]. The in situ expression of RCR in C. parapsilosis may provide the appropriate environment for correct protein-folding and improve its catalytic activity. C. parapsilosis is the major fungal pathogen and is of significant medical and biotechnological importance, so the successful genetic manipulation of this fungus will ultimately lead to the identification of valuable new biotechnological processes [21]. The genetic manipulation of Candida species has been challenging because they lack natural plasmids $[22,23]$. The reported gene disruption method in Candida strains by Reuß et al. [24-26] and the molecular genetics of Candida albicans by De Backer et al. [27] might supply convenient technical information for in situ protein expression in Candida species.

In this work, to improve the biotransformation efficiency of racemic $(R, S)$-PED to its $(S)$-isomer by C. parapsilosis through improving RCR activity to rebalance the functions of RCR and SCR, we designed a special vector pCP for in situ expression of RCR in C. parapsilosis. The catalytic efficiency of RCR was significantly enhanced, better rebalancing the RCR and SCR functions. Based on $\mathrm{pH}$ and temperature preferences of RCR and SCR, we proposed a two-stage control strategy to rebalance RCR and SCR-mediated asymmetric biosynthetic pathway. The in situ expression system C. parapsilosis/pCPRCR catalyzed racemic PED to (S)-PED with high optical purity of $98.8 \%$ and a high yield of $48.4 \%$. More importantly, the biotransformation process was decreased from 
48 to $13 \mathrm{~h}$. This work provides a method for improving chiral biosynthesis efficiency through the in situ expression of a rate-limiting enzyme and a two-stage $\mathrm{pH}$ and temperature control strategy to rebalance multi-enzyme mediated asymmetric pathways.

\section{Results}

Design of in situ expression system of RCR in C. parapsilosis The in situ expression plasmid pCP-rcr containing $6 \times$ Histagged RCR was constructed using standard techniques described in the "Methods" section. Briefly, a 5'-terminal 548-bp fragment of a mal2 ortholog was used to drive $r c r$ expression, and a 3'-terminal 388-bp fragment of an act 1 ortholog to terminate $r c r$ expression. An act1 promoter (1141 bp) and an ura3 terminator (508 bp) were used to control sat 1 expression, which conferred nourseothricin resistance in $C$. parapsilosis $[24,28]$. Since seven DNA fragments (ura $3 p$, mal $2 p$, rcr, act1t, act1p, sat1 and ura $3 t$ ) were cloned into pUC57 simultaneously to construct the recombinant pCP-rcr (Fig. 2), some of their restriction enzyme recognition sites were mutated, and the enzyme digestion and overlap-extension PCR techniques were both used. The length of expression cassette ura3p-mal $2 p$ rcr-act1t-act1p-salt-ura3t was about $4.5 \mathrm{~kb}$. Recombinant plasmid pCP-rcr was transformed into E. coli $\mathrm{DH} 5 \alpha$ competent cells to construct E. coli DH $5 \alpha / \mathrm{pCP}-r c r$. Subsequent nucleotide sequencing confirmed that the expression cassette ura3p-mal2p-rcr-act1t-act1p-salt-ura3t had been correctly cloned into $\mathrm{pCP}-r c r$ plasmid.

\section{In situ expression of RCR rebalanced the RCR and SCR functions}

EcoRI linearized pCP-rcr plasmid was transformed into C. parapsilosis by electroporation. C. parapsilosis/pCRrcr transformants were selected using nourseothricin as a positive selection marker and a uracil auxotroph as a negative selection marker. Colony PCR was carried out using RCR_1 and RCR_2 as primers, and subsequent nucleotide sequencing confirmed that the $r c r$ gene was integrated into the $C$. parapsilosis genome. SDS-PAGE analysis showed that a predominant band corresponding to the expected size of the $6 \times$ His-tagged RCR enzyme $(37 \mathrm{kDa})$ was observed in cell-free extracts of C. parapsilosis/pCR-rcr. The expression of recombinant RCR reached the highest level at $30 \mathrm{~h}$. The expression of RCR was obviously low in WT C. parapsilosis with a molecular size of $36 \mathrm{kDa}$ (Fig. 3a).

RCR has two functions including oxidation of $(R)-P E D$ to 2-HAP and reduction 2-HAP to (R)-PED. Recombinant $C$. parapsilosis/pCP-rcr showed a specific activity of $0.74 \mathrm{U} / \mathrm{mg}$ for $(R)-\mathrm{PED}$ oxidation, and $0.15 \mathrm{U} / \mathrm{mg}$ for 2-HAP reduction in the cell-free extracts, while WT $C$. parapsilosis presented $0.04 \mathrm{U} / \mathrm{mg}$ for $(R)-\mathrm{PED}$ oxidation, and $0.16 \mathrm{U} / \mathrm{mg}$ for $2-\mathrm{HAP}$ reduction (Table 1 ). The recombinant $C$. parapsilosis/pCP-rcr showed 4-5 folds higher oxidative and reductive activity than WT. But the two strains presented the same activity for reduction of 2 -HAP to $(S)$-PED in the cell-free extracts. The recombinant $C$. parapsilosis/pCP-rcr biotransformed racemic PED to its $(S)$-isomer with an optical purity of $95.6 \%$ and a yield of $43.5 \%$ in $30 \mathrm{~h}$. Compared to WT, recombinant C. parapsilosis/pCP-rcr improved the optical purity and yield of (S)-PED 3.4 and $32.6 \%$, respectively. Notably, the biotransformation process was shortened from 48 to $30 \mathrm{~h}$ (Table 1 ).

RCR and SCR mediated biotransformation of racemic PED to (S)-PED contains two steps: RCR catalyzes $(R)$ PED to 2-HAP; SCR catalyzes 2-HAP to $(S)$-PED. The kinetic parameters of RCR catalyzing $(R)$-PED oxidation and SCR catalyzing 2-HAP reduction were assessed in WT and recombinant C. parapsilosis/pCP-rcr. The recombinant $C$. parapsilosis/pCP-rcr showed about twofold higher $k_{c a t}$ value than WT, but maintained $K_{m}$ value towards (R)-PED oxidation. WT and recombinant $C$. parapsilosis/pCP-rcr showed almost the same $K_{m}$ and $k_{c a t}$

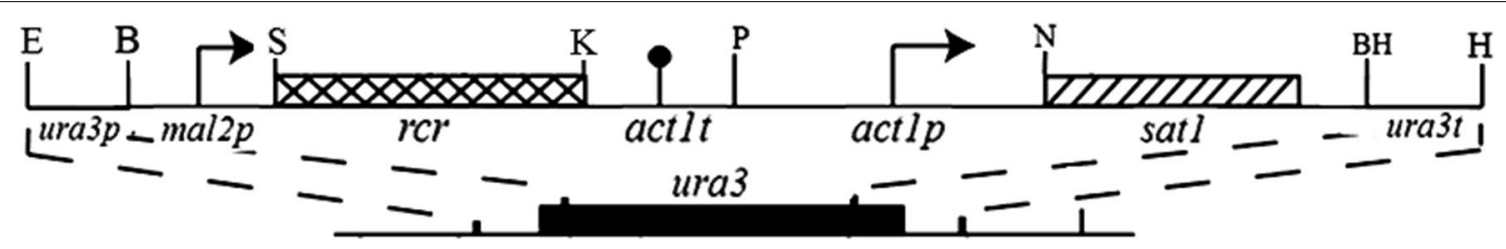

Fig. 2 Construction of an expression cassette for RCR in C. parapsilosis. ura3p (upstream sequence of ura3 gene) and ura3t (downstream sequence of ura3 gene) fragments were amplified using primers URA3p_1/URA3p_2 and URA3t_1/URA3t_2, and used as homologous regions for insertion into the genome. mal2p (upstream sequence of mal2 gene) and act1p (upstream sequence of act1 gene) fragments were amplified using primers MAL2p_1/MAL2p_2 and ACT1p_1/ACT1p_2, and used as the promoters for expression of the $r c r$ and sat1 genes, respectively. act1t (downstream sequence of act1 gene) and ura3t (downstream sequence of ura3 gene) fragments were amplified using primers ACT1t_1/ACT1t_2 and URA3t_1/ URA3t_2, and used as the terminators for the rcr and sat 1 genes, respectively. Restriction sites are unique. E EcoRl, B Bg/ll, S Sacl, K K Knnl, P Pstl, N Notl, BH BamHI, H Hind III 


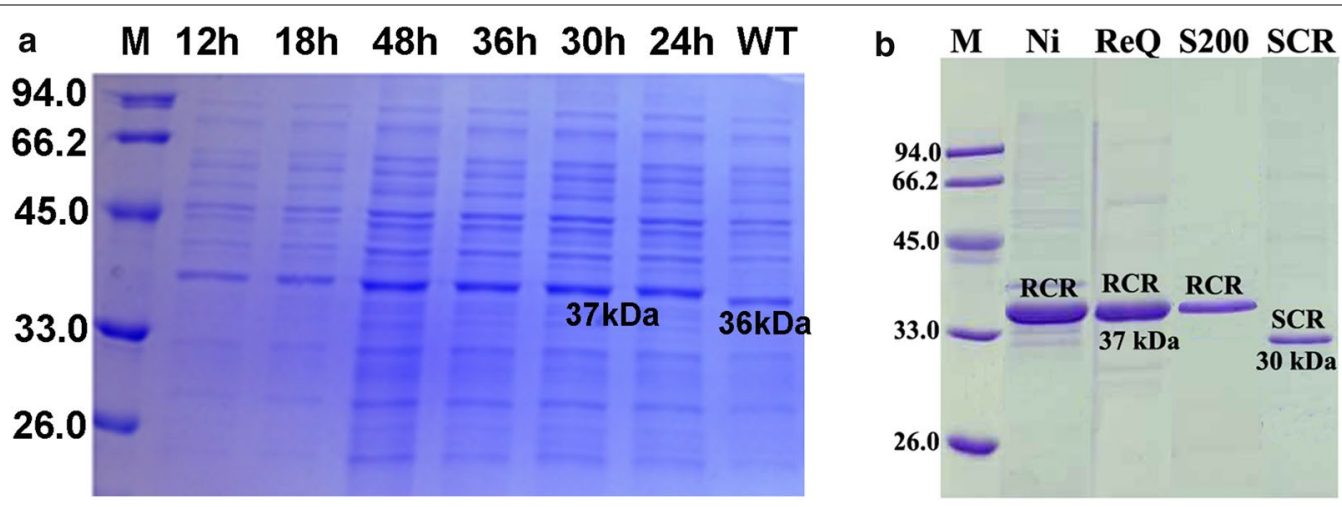

Fig. 3 a SDS-PAGE analysis of RCR expression at different time points in recombinant C. parapsilosis/pCP-RCR. The cell-free extracts of $C$. parapsilosis/ pCP-RCR collected at different time points were separated on $15 \%$ polyacrylamide gels. Lane M, protein molecular standards. b SDS-PAGE analysis of purified RCR. ReQ the fraction purified by Resource Q chromatography; S200 the fraction purified by Superdex-200 chromatography; SCR purified SCR from C. parapsilosis/pCP-RCR; Lane M, protein molecular standards

values towards 2-HAP reduction (Table 2). The relative $k_{\text {cat }} / K_{m}$ of RCR and SCR was 2.08 in WT C. parapsilosis, while it was 1.14 in C. parapsilosis/pCP-rcr (Table 2), suggesting the better rebalance of RCR and SCR functions.

\section{Purification of RCR and SCR and their temperature and $\mathrm{pH}$ dependence}

Recombinant RCR with a C-terminal $\mathrm{His}_{6}$-tag was purified using the standard technique in the "Methods" section. The proteins were purified to apparent homogeneity by SDS-PAGE (Fig. 3b). SCR was purified from the recombinant $C$. parapsilosis/pCP-rcr according to methods described by Zhang et al. [17].

The $\mathrm{pH}$ and temperature dependences of purified RCR were determined. The recombinant RCR showed its optimal pH 5.0 and $30{ }^{\circ} \mathrm{C}$ for catalyzing (R)-PED to 2-HAP, and $\mathrm{pH} 6.5$ and $35^{\circ} \mathrm{C}$ for catalyzing 2-HAP to $(R)$-PED at $\mathrm{pH} 6.5$ and $35^{\circ} \mathrm{C}$ (Additional file 1: Figures S1, S2). When

Table 1 The specific activities of RCR and SCR in the cell-free extracts of recombinant C. parapsilosis/pCP-rcr and wildtype C. parapsilosis

\begin{tabular}{|c|c|c|c|c|c|c|}
\hline \multirow[t]{2}{*}{ Cell-free extracts } & \multicolumn{2}{|l|}{$\mathrm{RCR}^{\mathrm{a}}$} & \multirow{2}{*}{$\begin{array}{l}\text { SCR } \\
\text { Reductive activities (U/mg) } \\
2-H A P \rightarrow(S) \text {-PED }\end{array}$} & \multicolumn{3}{|c|}{ Biotransformation } \\
\hline & $\begin{array}{l}\text { Oxidative activi- } \\
\text { ties }(\mathrm{U} / \mathrm{mg})(R)- \\
\text { PED } \rightarrow 2 \text {-HAP }\end{array}$ & $\begin{array}{l}\text { Reductive } \\
\text { activities (U/mg) } \\
2-\mathrm{HAP} \rightarrow(R)-\mathrm{PED}\end{array}$ & & $\begin{array}{l}\text { Optical purity } \\
(\%)\end{array}$ & Yield (\%) & $\begin{array}{l}\text { Duration } \\
\text { (h) }\end{array}$ \\
\hline C.parapsilosis & $0.04 \pm 0.00$ & $0.16 \pm 0.08$ & $0.39 \pm 0.03$ & $92.5 \pm 1.7$ & $32.8 \pm 0.8$ & 48 \\
\hline C. parapsilosis/pCP-rer & $0.15 \pm 0.01$ & $0.74 \pm 0.07$ & $0.40 \pm 0.04$ & $95.6 \pm 2.1$ & $43.5 \pm 1.0$ & 30 \\
\hline
\end{tabular}

a The reductive activities of RCR catalyzing ( $R$ )-PED to 2-HAP were determined using NADH as cofactor. The oxidative activities of RCR catalyzing 2-HAP to $(R)$-PED were determined using $\mathrm{NAD}^{+}$as cofactor

Table 2 Kinetic parameters for oxidation of (R)-PED to 2-HAP by RCR and reduction of 2-HAP to (S)-PED by SCR in recombinant C. parapsilosis/pCP-rcr and wild-type C. parapsilosis

\begin{tabular}{|c|c|c|c|c|c|c|c|}
\hline \multirow[t]{2}{*}{ Strains } & \multicolumn{3}{|c|}{ Oxidation of $(R)$-PED to 2-HAP by RCR } & \multicolumn{3}{|c|}{ Reduction of 2-HAP to (S)-PED by SCR } & \multirow[t]{2}{*}{ Relative $^{\mathrm{a}} k_{\text {cat }} / K_{m}$} \\
\hline & $K_{m}(\mathrm{mM})$ & $k_{\text {cat }}\left(\mathrm{S}^{-1}\right)$ & $k_{\text {cat }} / K_{m}\left(\mathrm{~S}^{-1} \mathrm{mM}^{-1}\right)$ & $K_{m}(\mathrm{mM})$ & $k_{\text {cat }}\left(\mathrm{S}^{-1}\right)$ & $k_{\text {cat }} / K_{m}\left(\mathrm{~S}^{-1} \mathrm{mM}^{-1}\right)$ & \\
\hline C. parasilosis & $6.53 \pm 0.20$ & $1.88 \pm 0.14$ & 0.29 & $4.36 \pm 0.13$ & $2.58 \pm 0.05$ & 0.59 & 2.03 \\
\hline C. parapsilosis/pCP-rcr & $6.31 \pm 0.09$ & $3.19 \pm 0.22$ & 0.51 & $4.39 \pm 0.10$ & $2.53 \pm 0.02$ & 0.58 & 1.14 \\
\hline
\end{tabular}

All reactions involved in the calculation of kinetics constants were assayed with $100 \mathrm{mM}$ acetate buffer $(\mathrm{pH} 6.5)$ at $35^{\circ} \mathrm{C}$. All experiments were repeated three to five times

a Relative $k_{\text {cat }} / K_{m}$ between oxidation of $(R)$-PED to 2 -HAP by RCR and reduction of 2-HAP to (S)-PED by SCR 
RCR was kept at temperatures below $40^{\circ} \mathrm{C}$ for $1 \mathrm{~h}$ or $\mathrm{pH}$ 4.5-6.5 for $48 \mathrm{~h}$, it retained $>70 \%$ of its maximum oxidative and reductive activity (Additional file 1: Figures S1, S2).

The enzyme SCR was purified from recombinant $C$. parapsilosis/pCP-rcr. It showed its optimal $\mathrm{pH} 4.5$ and $35{ }^{\circ} \mathrm{C}$ for catalyzing 2-HAP to (S)-PED at $\mathrm{pH} 4.5$ and $35{ }^{\circ} \mathrm{C}$. When SCR was incubated at $\mathrm{pH} 4.0-7.0$ for $48 \mathrm{~h}$ or $40{ }^{\circ} \mathrm{C}$ for $1 \mathrm{~h}$, about $80 \%$ of its maximum activity was retained (Additional file 1: Figures S3, S4).

\section{The biotransformation of (R)-PED to (S)-isomer under the optimum conditions of RCR and SCR}

Under the optimum conditions for RCR catalyzing $(R)$ PED to 2-HAP (i.e., pH 5.0 and $30{ }^{\circ} \mathrm{C}$ ), the recombinant $C$. parapsilosis/pCP-rcr cells converted racemic $(R, S)$-PED to $(S)$-PED and the reaction reached a good balance in $24 \mathrm{~h}$. At that time, the consumption rate of $(R)$-PED and the formation rate of $(S)$-isomer was almost the same, and 2-HAP was maintained at a stable level (Fig. 4a). (S)-PED was produced with an optical purity of $93.7 \%$ and a yield of $46.5 \%$.

Under the optimum conditions for RCR catalyzing 2-HAP to $(R)$-PED (i.e., $\mathrm{pH} 6.5$ and $35{ }^{\circ} \mathrm{C}$ ), There are three distinct stages during the biotransformation of racemic $(R, S)$-PED to $(S)$-PED by recombinant $C$. parapsilosis/pCP-rcr. In the initial stage (0-12 h), (R)-PED was transformed to 2-HAP. But the intermediate 2-HAP could not be rapidly transformed to (S)-PED, resulted in 2-HAP accumulation to the highest level $(1.5 \mathrm{~g} / \mathrm{L})$ at $12 \mathrm{~h}$ (Fig. 4b). At that time, the ratio of the concentration of
$(R)$-PED to $(S)$-PED was about 2:1. In the middle stage $(12-16 \mathrm{~h})$, the intermediate 2-HAP was almost completely consumed and transformed to (R)-PED. In the final stage (16-55 h), (R)-PED concentration gradually decreased and was transformed to 2-HAP by RCR; and 2-HAP was then rapidly converted to (S)-PED by SCR until the (R)-PED was almost completely consumed (Fig. 4b). Finally, recombinant C. parapsilosis/pCP-rcr catalyzed racemic mixture to its $(S)$-PED with an optical purity of $94.7 \%$ and a yield of $48.1 \%$ in $55 \mathrm{~h}$.

\section{Significantly improved biotransformation efficiency of (S)-PED using a two-stage control strategy}

To improve stereoinversion efficiency of racemic $(R, S)$ PED to (S)-PED and shorten biotransformation duration, a two-stage control strategy was devised based on the optimal conditions of two sequential reactions: RCR catalyzing $(R)$-PED to 2-HAP and SCR catalyzing 2-HAP to $(R)$-PED. In an asymmetric $10-\mathrm{mL}$ reactor, the $\mathrm{pH}$ and temperature were initially set at 5.0 and $30{ }^{\circ} \mathrm{C}$ for RCR rapidly catalyzing (R)-PED to 2-HAP (Fig. 5). The initial level of $10 \mathrm{~g} / \mathrm{L}$ racemic $(R, S)$-PED quickly decreased and most of substrate was consumed in $8 \mathrm{~h}$ by recombinant C. parapsilosis/pCP-rcr. At that time, the intermediate 2-HAP reached its highest level $(1.8 \mathrm{~g} / \mathrm{L})$. Then the biotransformation conditions were adjusted to $35{ }^{\circ} \mathrm{C}$ and $\mathrm{pH} 4.5$ for SCR quickly converting 2-HAP to (S)-PED. The residual substrate racemic $(R, S)$-PED and the intermediate 2-HAP were both consumed and transformed to (S)-PED from $8 \mathrm{~h}$ to $13 \mathrm{~h}$ (Fig. 5). During the final stages (from 12 to $13 \mathrm{~h}$ ), there was few residual intermediate
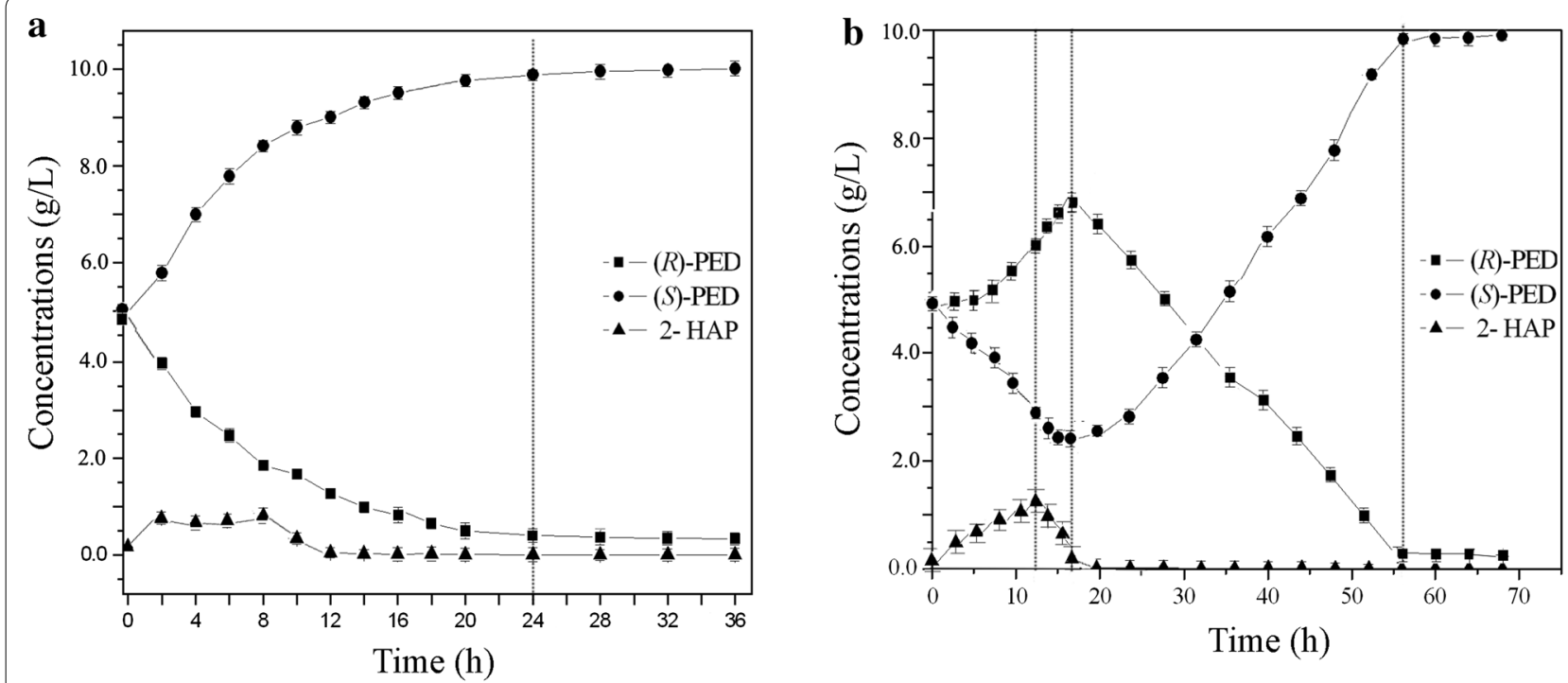

Fig. 4 The biotransformation course of racemic (R,S)-PED to its (S)-isomer by recombinant C. parapsilosis/pCP-RCR cells. a Biotransformation carried out using 2-HAP as substrate; b biotransformation carried out using racemic $(R, S)$-PED as substrate 


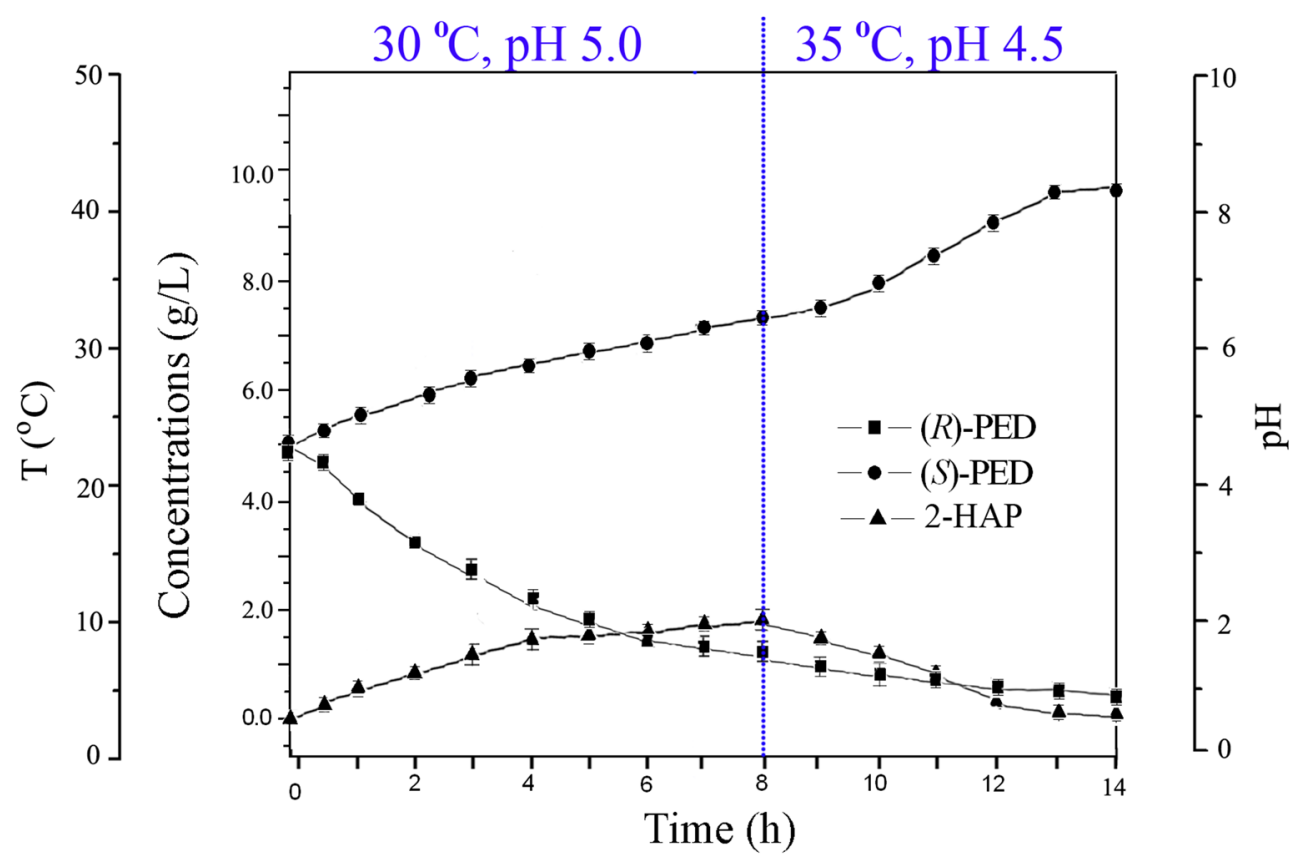

Fig. 5 Optimized biotransformation of racemic (R,S)-PED to its (S)-isomer through a two-stage control strategy. The temperature and $\mathrm{pH}$ were set at $30^{\circ} \mathrm{C}$ and 5.0 in $8 \mathrm{~h}$, and then converted at $35^{\circ} \mathrm{C}$ and 4.5 from 9 to $13 \mathrm{~h}$. The recombinant C. parapsilosis/pCP-RCR cells catalyzed racemic (R,S)-PED to its (S)-isomer with a high optical purity ( $98.8 \%$ ) and a yield of $48.4 \%$ within $13 \mathrm{~h}$ without addition of cofactors

2-HAP. Finally, recombinant C. parapsilosis/pCP-rcr catalyzed racemic mixture to $(S)$-PED with an optical purity of $98.8 \%$ and a yield of $48.4 \%$ in $13 \mathrm{~h}$.

\section{Discussion}

Candida parapsilosis transformes racemic PED to its $(S)$ isomer including two steps: RCR catalyzes the oxidation of $(R)$-PED to 2-HAP, and SCR catalyzes the reduction of 2-HAP to (S)-PED. However, C. parapsilosis and recombinant E. coli-RCR-SCR catalyzed the biotransformation of (S)-PED with a yield of 75-83\%, and the process required a long time (48 $\mathrm{h})[8,9]$. By analysis of RCR and SCR functions, we found that SCR showed much higher overall activity than RCR, which may be due to its exhibiting more correct protein folding and higher protein expression in C. parapsilosis and other host cells [8, 29]. Moreover, a cluster of four SCR isozymes was recently found in C. parapsilosis [30], which enlarged the activity gap between RCR and SCR.

In this work, we designed a special expression plasmid pCP by cloning the expression components into pUC57, and introduced an in situ expression system of RCR into C. parapsilosis to strengthen RCR function. To improve screening probability of the positive C. parapsilosis/pCP$r c r$ clones, the RCR expression cassette was designed using nourseothricin as a positive selection marker and a uracil auxotroph as a negative selection marker. The minimal inhibitory concentration of nourseothricin was $60 \mu \mathrm{g} / \mathrm{ml}$ in C. parapsilosis. Reuss et al. used the drug nourseothricin as a dominant selectable marker for gene disruption in C. albicans [31]. Shen et al. used the nourseothricin adapted to suit $C$. albicans in a Ca-NAT1-FLP cassette [32]. However, the concentration of nourseothricin used in C. albicans was different from that of in $C$. parapsilosis which may be due to the different resistance levels of two Candida strains. Using this screening technique, we selected the clones with the highest activities from about 120 positive C. parapsilosis clones.

The constitutive expression of $6 \times$ his tagged RCR strengthened its function in C. parapsilosis. The recombinant $C$. parapsilosis/pCP-rcr showed over fourfold higher activities for catalyzing (R)-PED to 2-HAP than WT, which may be due to the integration of several copies of the RCR gene into the C. parapsilosis genome [21, 33]. The introduction of in situ expression of RCR had no effect on the cell-growth and SCR activity. The in situ expression of RCR did not change $K_{m}$ value towards $(R)$ PED oxidation, and $K_{m}$ and $k_{c a t}$ values towards 2-HAP reduction, but increased $k_{c a t}$ value towards (R)-PED oxidation about two times. The relative $k_{c a t} / K_{m}$ of SCR catalyzing 2-HAP and RCR catalyzing (R)-PED was about 2 in WT C. parapsilosis, indicating the imbalance between RCR and SCR functions, with SCR performing at a higher rate than RCR. The relative $k_{c a t} / K_{m}$ value was about 1 
in C. parapsilosis/pCP-rcr, suggesting good rebalance between RCR and SCR functions. The obviously higher $k_{c a t} / K_{m}$ value of RCR in C. parapsilosis/pCP-rcr than that of in WT may be due to the $6 \times$ histine tag at $\mathrm{N}$-terminal of RCR in C. parapsilosis/pCP-rcr. Yeon et al. thought that the catalytic activity of 3-hydroxybutyrate dehydrogenase was not severely affected by the $\mathrm{N}$-terminal Histag due to the location of the $\mathrm{N}$-terminus far from the active site of the enzyme [34]. Dickson et al. reported that the $\mathrm{N}$-terminus His-tag did result in a differential effect on protein kinase activity, further potentiating the elevated protein kinase activity of both the helical domain and catalytic domain oncogenic mutants with relation to p110 phosphorylation [35]. The introduction of in situ expression of RCR better rebalanced RCR and SCR functions, resulting in obviously improved optical purity and yield of (S)-PED during the biotransformation of racemic PED to its $(S)$-isomer. Compared to WT, the recombinant $C$. parapsilosis/pCP-rcr reduced the biotransformation duration from 48 to $36 \mathrm{~h}$.

To further improve the stereoconversion efficiency of racemic $(R, S)$-PED to its $(S)$-isomer by recombinant C. parapsilosis/pCP-rcr, the biotransformation process should be optimized. Since RCR not only catalyzes oxidation of (R)-PED to 2-HAP, but also catalyzes reduction of 2-HAP to $(R)$-PED. The latter function is unfavorable for the biotransformation of racemic PED to (S)-PED. By analysis of the whole biotransformation process, we found much time was wasted in the reversible reaction between 2-HAP and (R)-PED. Basing on $\mathrm{pH}$ and temperature preferences of RCR catalyzing $(R)$-PED to 2-HAP and SCR catalyzing 2-HAP to (S)-PED, we envisaged a two-stage control strategy to optimize the asymmetric biotransformation process. The biotransformation was first carried out under the optimal conditions for RCR rapidly catalyzing (R)-PED to 2-HAP, then under the optimal conditions for SCR converting 2-HAP to (S)-PED. Using these strategies, the recombinant C. parapsilosis/pCP-rcr strains efficiently converted racemic $(R, S)$-PED to the $(S)$-isomer with good performance: an optical purity of $98.8 \%$ and a yield of $48.4 \%$. Since racemic $(R, S)$-PED contains $50 \%(S)$-PED, the final yield of (S)-PED by the recombinant C. parapsilosis/pCP-rcr is 98.4 \%. Zhang et al. reported one-step biotransformation of $(R)$-PED to $(S)$-isomer by an enzyme-coupled system $E$. coli/pET-RCR-SCR. The system produced (S)-PED with an optical purity of $91.3 \%$ and a yield of $75.9 \%$ in $48 \mathrm{~h}$ [8]. Nie et al. enhanced the biotransformation efficiency of $(R, S)$-PED to its $(S)$-isomer with an optical purity of $98.2 \%$ and a yield of $82.9 \%$ in $48 \mathrm{~h}$ using agitation speed control strategy during cell cultivation of C. parapsilosis CCTCC 203011 [9]. Compared with the E. coli/pETRCR-SCR and WT C. parapsilosis, the recombinant $C$.
parapsilosis/pCP-rcr increased the yield of (S)-PED about 18.7-29.3 \%. More importantly, the biotransformation time was reduced about four-fold: from 48 to $13 \mathrm{~h}[8,9]$.

\section{Conclusions}

There is much imbalance between the activities of RCR and SCR, resulting in a low biotransformation efficiency of racemic $(R, S)$-PED to its $(S)$-isomer by C. parapsilosis. In this work, we designed an in situ expression plasmid, pCP, and expressed RCR in C. parapsilosis to narrow the function gap between RCR and SCR. Then we developed a two-stage control strategy based on $\mathrm{pH}$ and temperature preferences of RCR and SCR. The in situ expression system biotransformed racemic $(R, S)$-PED to its $(S)$-isomer with good performance: an optical purity of $98.8 \%$ and a yield of $48.4 \%$. Most notably, the biotransformation duration was reduced about four times: from 48 to $13 \mathrm{~h}$ with respect to the WT. This work provides a method for improving chiral biosynthesis efficiency through in situ expression of a rate-limiting enzyme and a two-stage control strategy to rebalance asymmetric pathways. Further research will be carried out using the safer microbial hosts for more efficient protein expression and chiral biosynthesis.

\section{Methods}

Chemicals

NADPH and 2-HAP were obtained from SigmaAldrich Chemical Co., Inc. (St. Louis, USA). Restriction enzymes, nourseothricin, uracil and 5-fluoroorotic acid were obtained from Takara Bio. Co. (Kyoto, Japan). All other chemicals were of the high grade commercially obtainable.

\section{Organisms and culture conditions}

Candida parapsilosis CCTCC M203011 was obtained from the American Type Culture Collection. It was cultured in yeast extract peptone-dextrose medium $(1 \%$ yeast extract, $2 \%$ glucose, $2 \%$ peptone) at $30{ }^{\circ} \mathrm{C}$. E. coli DH $5 \alpha$ was grown in lysogeny broth medium $(0.5 \%$ yeast extract, $1 \% \mathrm{NaCl}, 1 \%$ peptone) at $37^{\circ} \mathrm{C}$. When nesseary, $60 \mu \mathrm{g} / \mathrm{ml}$ nourseothricin and $20 \mu \mathrm{g} / \mathrm{ml}$ uracil was added. Recombinant C. parapsilosis were cultured in medium containing $0.5 \%$ yeast extract, $4 \%$ maltose, $1.3 \%$ $\left(\mathrm{NH}_{4}\right)_{2} \mathrm{HPO}_{4}, 0.7 \% \mathrm{KH}_{2} \mathrm{PO}_{4}, 0.01 \% \mathrm{NaCl}$, and $0.08 \%$ $\mathrm{MgSO}_{4} \cdot 7 \mathrm{H}_{2} \mathrm{O}$ with the addition of $60 \mu \mathrm{g} / \mathrm{ml}$ nourseothricin and $20 \mu \mathrm{g} / \mathrm{ml}$ uracil.

\section{Construction of the in situ expression plasmid pCP-rcr}

Plasmids, strains and primers used in this work are listed in Additional file 1: Table S1 in the supplemental material. The SAT1-flipper method and ura3-negative method were used to construct the RCR in situ expression 
plasmid for C. parapsilosis. The promoter act1A gene (GenBank ID: AJ389062.1) was amplified from the C. parapsilosis genome using primers ACT1p_1 and ACT1p_2, and was cloned into the corresponding NotI/ HindIII sites of pMD19-T (Takara Co., Dalian, China), resulting in the recombinant plasmid T-act1p. The sat1 gene (KF318043.1) (of 525-bp) was amplified with primers SAT1_1 and SAT1_2 (NotI/BamHI). The ura3 (3636649) downstream fragment (508 bp) was cloned using primers URA3t_1 and URA3t_2 (BamHI/HindIII). The sat1-ura3t fragment was generated using a modified overlap-extension technique [36] with the primers SAT1_1 and URA3t_2. The NotI/HindIII fragment of sat1-ura3t was inserted into plasmid T-act1p to generate the plasmid T-act1p-sat1-ura3t. The upstream sequence of ura3 (285-bp) was amplified with primers URA3p_1 and URA3p_2 (EcoRI/BglII), and the mal2 promoter (3638946) (548 bp) was amplified using primers MAL2p_1 and MAL2p_2 (BglII/SacI). The ura3p-mal2p fragment was generated using primers URA3p_1 and MAL2p_2. The EcoRI/SacI fragment of ura3p-mal $2 p$ was inserted into pUC57 to generate plasmid pUC57-ura3pmal2p. The $r c r$ gene (GenBank ID: DQ295067) with a 6× His-tag at the C-terminus was amplified from the C. parapsilosis genome with primers RCR_1 and RCR_2 (containing recognition sites for $S a c \mathrm{I}$ and $K p n \mathrm{I}$ ), and cloned into pUC57-ura3p-mal $2 p$ to generate pUC57-ura3pmal $2 p$-rcr. The act 1 downstream sequence (388-bp) was amplified with primers ACT1t_1 and ACT1t_2 (containing recognition sites for $K p n \mathrm{I}$ and $P s t \mathrm{I}$ ), and cloned into pUC57-ura3p-mal2p-rcr, generating pUC57-ura3pmal2p-rcr-act1t. The plasmid T-act1p-sat1-ura3t was digested with PstI and HindIII and then inserted into pUC57-ura3p-mal $2 p$-rcr-act1t, generating the recombinant plasmid pUC57-ura3p-mal2p-rcr-act1t-act1p-saltura3t, named pCP-rcr. All the recombinant plasmids were verified by DNA sequencing.

\section{Electrotransformation of C. parapsilosis}

Candida parapsilosis cells were cultured overnight until the $O D_{600}$ value reached 2.0, and were then inoculated into $50 \mathrm{ml}$ yeast extract peptone-dextrose medium at $30{ }^{\circ} \mathrm{C}$. When the $O D_{600}$ value of the culture reached 1.02.0, the culture was resuspended in $50 \mathrm{ml}$ of Tris-EDTA buffer ( $\mathrm{pH} 7.5$ ) containing $10 \mathrm{mM}$ dithiothreitol, and was then kept on ice for $30 \mathrm{~min}$. After the cells were washed four times using $10 \mathrm{ml}$ of $1 \mathrm{M}$ ice-cold sorbitol, the competent cells were resuspended in $80 \mu \mathrm{l} 1 \mathrm{M}$ sorbitol. The vector pCP-rcr was linearized with EcoRI and then transformed into C. parapsilosis with a MicroPulser electroporator (Bio-Rad, USA) at $2000 \mathrm{~V}$ in a 1-mm cuvette. After electroporation, $1 \mathrm{ml}$ of ice-cold $1 \mathrm{M}$ sorbitol was immediately added. The cells were incubated at $30{ }^{\circ} \mathrm{C}$ for $2 \mathrm{~h}$ and collected at $4000 \times g$ for $10 \mathrm{~min}$. After resuspension in $100 \mu \mathrm{l}$ sorbitol $(1 \mathrm{M})$, the cultures were plated onto minimal dextrose plates containing $60 \mu \mathrm{g} / \mathrm{ml}$ nourseothricin and $20 \mu \mathrm{g} / \mathrm{ml}$ uracil. The C. parapsilosis/pCR-rcr transformants were obtained after incubation for $48 \mathrm{~h}$.

\section{Cell-free extract preparation}

Recombinant C. parapsilosis cells were grown for $48 \mathrm{~h}$ in medium containing $0.5 \%$ yeast extract, $4 \%$ maltose, $1.3 \%\left(\mathrm{NH}_{4}\right)_{2} \mathrm{HPO}_{4}, 0.7 \% \mathrm{KH}_{2} \mathrm{PO}_{4}, 0.01 \% \mathrm{NaCl}$, and $0.08 \% \mathrm{MgSO}_{4} \cdot 7 \mathrm{H}_{2} \mathrm{O}$. When necessary, $60 \mu \mathrm{g} / \mathrm{ml}$ nourseothricin was added into the medium. The cells were harvested by centrifugation and washed twice with $0.8 \%$ $\mathrm{NaCl}$ solution, and then suspended in $0.1 \mathrm{M}$ potassium phosphate buffer (pH 6.5). WT C. parapsilosis and recombinant $C$. parapsilosis/pCR-rcr cells were harvested and broken using an APV 2000 homogenizer (SPX Co. Unna, Germany). The homogenate was centrifuged at $48,000 \times g$ for $40 \mathrm{~min}$. The supernatant of WT C. parapsilosis and recombinant C. parapsilosis/pCR-rcr was used for further enzyme assay and protein purification.

\section{Enzyme assay}

The mixture for assaying reductive activity of RCR contained $0.1 \mathrm{M}$ potassium phosphate buffer ( $\mathrm{pH} 6.5$ ), $0.5 \mathrm{mM} \mathrm{NADH} / \mathrm{NADPH}, 5 \mathrm{mM} 2-\mathrm{HAP}$, and an appropriate amount of RCR or the cell-free extracts of WT and recombinant C. parapsilosis/pCR-rer in a total volume of $100 \mu \mathrm{l}$. The mixture for assaying oxidative activity of RCR comprised $0.1 \mathrm{M}$ potassium phosphate buffer $(\mathrm{pH}$ 6.5), $0.5 \mathrm{mM} \mathrm{NAD}{ }^{+}, 5 \mathrm{mM}(R)$-PED, and an appropriate amount of RCR or cell-free extracts of WT and C. parapsilosis/pCR-rcr in a total volume of $100 \mu$ l. The decrease/ increase in the concentration of $\mathrm{NAD}(\mathrm{P})^{+}$or $\mathrm{NAD}(\mathrm{P})$ $\mathrm{H}$ was recorded spectrophotometrically at $340 \mathrm{~nm}$. The reduction activity of SCR was measured as described by Zhang et al. [13]. One unit of enzyme activity was defined as the amount of enzyme catalyzing the oxidation/reduction of $1 \mu \mathrm{mol} \mathrm{NAD}(\mathrm{P}) \mathrm{H} / \mathrm{NAD}(\mathrm{P})^{+}$per minute in the assay conditions. The protein concentration was determined using Bradford reagent (Bio-Rad) with bovine serum albumin as the standard [37]. Reported values represent the average of at least three independent measurements.

\section{Temperature and $\mathrm{pH}$ dependence of enzymes}

The temperature dependence of enzyme activity was determined from 10 to $60^{\circ} \mathrm{C}$. The $\mathrm{pH}$ dependence of the reductive activity was determined between $\mathrm{pH} 4.0$ and 9.0 using $100 \mathrm{mM}$ citrate buffer (pH 3.0-4.5), $100 \mathrm{mM}$ sodium acetate buffer ( $\mathrm{pH} 4.0-6.0), 100 \mathrm{mM}$ potassium phosphate buffer ( $\mathrm{pH} 6.0-7.0)$ or $100 \mathrm{mM}$ Tris-HCl buffer $(\mathrm{pH} 7.0-9.0)$ at $35{ }^{\circ} \mathrm{C}$. The enzyme activity was 
otherwise measured with the standard assay method described above.

\section{Stability of enzymes}

Thermostability was determined by incubation of the purified RCR and SCR $(0.2 \mathrm{mg} / \mathrm{ml})$ in $100 \mathrm{mM} \mathrm{NaAC}$ HAC buffer, $\mathrm{pH}$ 6.0, at temperatures between 10 and $60{ }^{\circ} \mathrm{C}$. The $\mathrm{pH}$ stability of enzymes was determined by incubating purified enzyme at $\mathrm{pH} 3.0-9.0$ and $35{ }^{\circ} \mathrm{C}$. After exposure of enzyme to the indicated conditions for $1 \mathrm{~h}$, samples were taken to assay for residual activity.

\section{Protein purification}

Recombinant RCR were expressed in C. parapsilosis with a $\mathrm{His}_{6}$-tag. Cell-free fractions were applied to $\mathrm{Ni}^{2+}$ Sepharose affinity chromatography columns (HisTrap Kit, GE Healthcare, Uppsala, Sweden) using an ÄKTA Protein Purifier system. The pooled fractions were then loaded onto a Resource Q column $(1 \times 1 \mathrm{~cm})$ equilibrated with $20 \mathrm{mM}$ Tris- $\mathrm{HCl}(\mathrm{pH}$ 8.0). Finally, the fractions were applied to a Superdex 200 column (HiLoad $26 / 60$, preparation grade) for chromatography in a buffer containing $20 \mathrm{mM}$ Tris- $\mathrm{HCl}$ (pH 8.0) and $150 \mathrm{mM} \mathrm{NaCl}$. The homogeneity of purified enzymes was judged by Coomassie Brilliant Blue staining of SDS-PAGE.

\section{Determination of kinetic parameters}

To determine the kinetic parameters, various concentrations of substrate 2-HAP or (R)-PED $(0.5-20 \mathrm{mM})$, enzyme $(10-200 \mu \mathrm{M})$, and cofactors $\mathrm{NAD}^{+}$or NADPH $(0.5-5.0 \mathrm{mM})$ in $0.1 \mathrm{M} \mathrm{NaAC}-\mathrm{HAC}$ buffer $(\mathrm{pH} 6.5)$ at $35{ }^{\circ} \mathrm{C}$ were used. The data were fitted to the Michaelis-Menten equation by using a nonlinear least-square iterative method using KaleidaGraph (Synergy Software, Reading, PA). Three sets of kinetic parameters were obtained from three independent experiments and then simply averaged to yield the final estimates. The final estimates are shown with the standard errors for the three sets.

\section{Biotransformation and analytical methods}

The biotransformation was carried out as previously described [9] with minor modifications. The reaction mixture in $1 \mathrm{ml}$ contained $0.1 \mathrm{M}$ potassium phosphate buffer (pH 6.5), $10 \mathrm{mg}$ racemic (R,S)-PED, and $0.1 \mathrm{~g}$ wet cells at $35^{\circ} \mathrm{C}$, or $0.1 \mathrm{M} \mathrm{NaAC}-\mathrm{HAC}$ buffer (pH 5.0), $10 \mathrm{mg}$ racemic $(R, S)$-PED, and $0.1 \mathrm{~g}$ wet cells at $30{ }^{\circ} \mathrm{C}$. Reactions were carried out for $48 \mathrm{~h}$ with shaking at $220 \mathrm{rpm}$. Through a two-stage $\mathrm{pH}$ and temperature control strategy, the reaction mixture in $10 \mathrm{ml}$ contained $0.1 \mathrm{M}$ potassium phosphate buffer, $10 \mathrm{mg}$ racemic $(R, S)$-PED, and $1.0 \mathrm{~g}$ wet cells. The biotransformation was carried out at
$\mathrm{pH} 5.0$ and $30{ }^{\circ} \mathrm{C}$ for $8 \mathrm{~h}$, then at $\mathrm{pH} 4.5$ and $35{ }^{\circ} \mathrm{C}$ for $5 \mathrm{~h}$. The products were extracted with ethyl acetate and the organic layer was analyzed by high-performance liquid chromatography on a Chiralcel OB-H column (Daicel Chemical Ind. Ltd., Japan). The conditions for the HPLC analyses-mobile phase, hexane:isopropanol 9:1; flow rate: $0.4 \mathrm{ml} / \mathrm{min}$, operating column temperature: $38{ }^{\circ} \mathrm{C}$; and UV detector. The optical purity and yield of products were calculated using the following equations [9]:

$$
\begin{aligned}
\text { Optical purity }_{(R)-\mathrm{PED}}= & ((R)-\mathrm{PED}-(S)-\mathrm{PED}) / \\
& ((R)-\mathrm{PED}+(S)-\mathrm{PED}) \times 100 \%
\end{aligned}
$$

$\operatorname{Yield}_{(R)-\mathrm{PED}}=(R)-\mathrm{PED} / 2-\mathrm{HAP} \times 100 \%$

$(R)$-PED, (S)-PED and 2-HAP are measured in grams.

\section{Additional file}

Additional file 1. Supplemental data containing plasmids, list of primers and strains and additional results.

\section{Abbreviations}

2-HAP: 2-hydroxyacetophenone; PED: 1-phenyl-1,2-ethanediol; RCR: (R)carbonyl reductase; SCR: (S)-carbonyl reductase.

\section{Authors' contributions}

RZZ participated in the design of the study and drafted the manuscript; LW carried out the molecular genetic studies; $Y X$ conceived of the study and participated in its design and coordination and helped to draft the manuscript; HBL carried out the biotransformation experiments; XTZ performed the results analysis; JWJ participated in the sequence alignment; YHL helped to perform the HPLC experiments; RX helped to revise the manuscript; $Y N$ performed the biotransformation results analysis. All authors read and approved the final manuscript.

\section{Author details}

${ }^{1}$ Key Laboratory of Industrial Biotechnology of Ministry of Education and School of Biotechnology, Jiangnan University, Wuxi 214122, People's Republic of China. ${ }^{2}$ National Key Laboratory for Food Science, Jiangnan University, Wuxi 214122, People's Republic of China. ${ }^{3}$ Center for Advanced Biotechnology and Medicine, Rutgers University, Piscataway, NJ 08854, USA.

${ }^{4}$ Present Address: School of Biotechnology, Jiangnan University, 1800 Lihu Avenue, Wuxi 214122, People's Republic of China.

\section{Acknowledgements}

The authors are grateful to James Allen for improving English writing.

\section{Competing Interests}

The authors declare that they have no competing interests.

\section{Availability of data and material}

The datasets supporting the conclusions of this article are included in the article and its additional files.

\section{Funding}

This project was supported by the National Science Foundation of China (Nos. 3137010 and 21336009), Jiangsu Province Basic Research Program (No. BK20131101), the Fundamental Research Funds for the Central Universities (JUSRP51409B), Chinese New Century Excellent Talents Project of Chinese 
Ministry of Education (NCET-13-0833), the National Key Basic Research and Development Program of China (973 Program No. 2011CB710800), the National High Technology Research and Development Program of China (863 Program Nos. 2011AA02A209 and 2011AA02A210), and the Program of Introducing Talents of Discipline to Universities (No. 111-2-06).

\section{Received: 21 April 2016 Accepted: 3 August 2016}

Published online: 17 August 2016

\section{References}

1. Wei ZL, Lin GQ, Li ZY. Microbial transformation of 2-hydroxy and 2-acetoxy ketones with Geotrichum sp. Bioorg Med Chem. 2000;8:1129-37.

2. Cao L, Lee J, Chen W, Wood TK. Enantioconvergent production of $(R)$ 1-phenyl-1,2-ethanediol from styrene oxide by combining the Solanum tuberosum and an evolved Agrobacterium radiobacter AD1 epoxide hydrolases. Biotechnol Bioeng. 2006;94:522-9.

3. Panke S, Held M, Wubbolts M. Trends and innovations in industrial biocatalysis for the production of fine chemicals. Curr Opin Biotechnol. 2004;15:272-9.

4. Schmid A, Dordick JS, Hauer B, Kiener A, Wubbolts M, Witholt B. Industrial biocatalysis today and tomorrow. Nature. 2001;409:258-68.

5. Schoemaker HE, Mink D, Wubbolts MG. Dispelling the myths-biocatalysis in industrial synthesis. Science. 2003;299:1694-7.

6. Hummel W. New alcohol dehydrogenases for the synthesis of chiral compounds. Adv Biochem Eng Biotechnol. 2007;58:145-84.

7. Pandey RK, Fernandes RA, Kumar P. An asymmetric dihydroxylation route to enantiomerically pure norfluoxetine and fluoxetine. Tetrahedron Lett. 2002:43:4425-6.

8. Zhang RZ, Xu Y, Sun Y, Geng Y. Construction of an enzyme-coupled system consisting of $(R)$ - and (S)-specific carbonyl reductases for one step preparation of (S)-1-phenyl-1,2-ethanediol. Acta Microbiologica Sinica. 2009;49:204-9.

9. Nie Y, Xu Y, LV TF, Xiao R. Enhancement of Candida parapsilosis catalyzing deracemization of $(R, S)$-1-phenyl-1,2-ethanediol: agitation speed control during cell cultivation. J Chem Technol Biot. 2009;84:468-72.

10. Cregg JM, Cereghino JL. Higgins DR: recombinant protein expression in Pichia pastoris. Mol Biotechnol. 2000;16:23-52.

11. Blum A, Martin H-J, Maser E. Human 11ß-hydroxysteroid dehydrogenase 1: carbonyl reductase: recombinant expression in the yeast Pichia pastoris and Escherichia coli. Toxicology. 2000;144:113-20.

12. Charles R, Dunker AK, Sharkhnovich E. Disorder in protein structure and function. Pac Symp Biocomput. 1999:4:517-9.

13. Zhang RZ, XU Y, Xiao R, Wang SS, Zhang BT. Improved production of (R)-1-phenyl-1,2-ethanediol using Candida parapsilosis ( $R$ )-carbonyl reductase expressed in Pichia pastoris. Process Biochem. 2011;46:709-13.

14. Krondorfer I, Lipp K, Brugger D, Staudigl P, Sygmund C, Haltrich D, Peterbauer CK. Engineering of pyranose dehydrogenase for increased oxygen reactivity. PLoS ONE. 2014;9:e91145.

15. Zhang RZ, Geng YW, Xu Y, Sun Y, Xiao R. Improved production of (R)1-phenyl-1,2-ethanediol by a codon optimized $R$-specific carbonyl reductase from Candida parapsilosis in Escherichia coli. Appl Biochem Biotech. 2010;160:868-78.

16. Zhang RZ, Xu Y, Wang SS, Zhang BT. Expression and subcellular localization of (R)- and (S)-specific carbonyl reductases from Candida parapsilosis in Saccharomyces cerevisia. Acta Microbiologica Sinica. 2011:51:789-95.

17. Zhang RZ, Xu Y, Xiao R, Zhang BT, Wang L. Optimized expression of (S)-carbonyl reductase in Pichia pastoris for efficient production of (S)1-phenyl-1, 2-ethanedio. J Basic Microb. 2014;8:873-9.
18. Yang TW, Rao ZM, Zhang X, Xu MJ, Xu ZH. Improved production of 2,3-butanediol in Bacillus amyloliquefaciens by over-expression of glyceraldehyde-3-phosphate dehydrogenase and 2,3-butanediol dehydrogenase. PLoS ONE. 2013;8:e76149.

19. Piskin G, Sylva-Steenland R, Bos J, Teunissen M. In vitro and in situ expression of IL-23 by keratinocytes in healthy skin and psoriasis lesions: enhanced expression in psoriatic skin. J Immun. 2006;176:1908-15.

20. Kasai T, Shozu M, Murakami K, Segawa T, Shinohara K, Nomura K, Inoue M. Increased expression of type I 17beta-hydroxysteroid dehydrogenase enhances in situ production of estradiol in uterine leiomyoma. J Clin Endocrinol Metab. 2004:89:5661-8.

21. Nosek J, Adamíková L, Zemanová J, Tomáska L, Zufferey R, Mamoun C. Genetic manipulation of the pathogenic yeast Candida parapsilosis. Curr Genet. 2002;42:27-35.

22. Magee PT, Gale C, Berman J, Davis D. Molecular genetic and genomic approaches to the study of medically important fungi. Infect Immun. 2003;71:2299-309.

23. Morschhäuser J, Michel S, Staib P. Sequential gene disruption in Candida albicans by FLP-mediated site-specific recombination. Mol Microbiol. 1999:32:547-56.

24. Reuß O, Vik $\AA$, Kolter R, Morschhäuser J. The SAT1 flipper, an optimized tool for gene disruption in Candida albicans. Gene. 2004;341:119-27.

25. Ding C, Butler G. Development of a gene knockout system in Candida parapsilosis reveals a conserved role for BCR1 in biofilm formation. Eukaryot Cell. 2007;6:1310-9.

26. Wilson R, Davis D, Enloe B, Mitchell A. A recyclable Candida albicans URA3 cassette for PCR product-directed gene disruptions. Yeast. 2000;16:65-70.

27. De Backer MD, Magee PT, Pla J. Recent developments in molecular genetics of Candida albicans. Annu Rev Microbiol. 2000:54:463-98.

28. Joshi PB, Webb JR, Davies JE, McMaster WR. The gene encoding streptothricin acetyltransferase (SAT) as a selectable marker for Leishmania expression vectors. Gene. 1995;156:145-9.

29. Zhang RZ, Xu Y, Xiao R, Zhang BT, Wang L. Efficient one-step production of (S)-1-phenyl-1,2-ethanediol from (R)-enatiomer plus NAD ${ }^{+}-\mathrm{NADPH}$ in situ regeneration using engineered Escherichia coli. Microb Cell Fact. 2012;11:167-75.

30. Nie Y, Xiao R, Xu Y, Montelione GT. Novel anti-Prelog stereospecific carbonyl reductases from Candida parapsilosis for asymmetric reduction of prochiral ketones. Org Biomol Chem. 2011;9:4070-8.

31. Reuss O, Vik A, Kolter R, Morschhäser J. The SAT1 flipper, an optimized too for gene disruption in Candida albicans. Gene. 2004;341:119-27.

32. Shen J, Guo W, Köler J. CaNAT1, a heterologous dominant selectable marker for transformation of Candida albicans and other pathogenic Candida species. Infect Immun. 2005:3:1239-42.

33. Teixeira JA, Nogueira GB, Queiroz MVd, Araújo EFd. Genome organization and assessment of high copy number and increased expression of pectinolytic genes from Penicillium griseoroseum: a potential heterologous system for protein production. J Ind Microbiol Biotechnol. 2014;41:1571-80.

34. Yeon $Y$, Park H, Park H, Yoo Y. Effect of His-tag location on the catalytic activity of 3-hydroxybutyrate dehydrogenase. Biotechnol Bioproc E. 2014:19:798-802.

35. Dickson J, Lee W, Shepherd P, Buchanan C. Enzyme activity effects of $\mathrm{N}$-terminal His-tag attached to catalytic sub-unit of phosphoinositide3-kinase. Bioscience Rep. 2013;33:857-63.

36. Ho SN, Hunt HD, Horton RM, Pullen JK, Pease LR. Site-directed mutagenesis by overlap extension using the polymerase chain reaction. Gene. 1989;77:51-9.

37. Bradford MM. A rapid and sensitive method for the quantitation of microgram quantities of protein utilizing the principle of protein dye binding. Anal Biochem. 1976:72:248-54. 